\title{
Habitação na Sociedade de Informação: Configurador de Design para o Mercado Imobiliário Brasileiro
}

\author{
Habitação na Sociedade de Informação: Configurador de Design para o Mercado Imobiliário Brasileiro
}

\author{
Camila Barbosa Curi \\ Universidade de Brasília, Brasil \\ camilabcuri@gmail.com \\ Neander Furtado Silva \\ Universidade de Brasilia, Brasil \\ neander.furtado@gmail.com
}

\begin{abstract}
In this paper, we present preliminary specifications for a computer design tool for the application of mass customization in middle class apartment design in Brazil. Believing that in the digital era, network communication and digital design tools combined may create a design environment that considers consumer needs and preferences, we present a simple drafting of a computer tool that makes use of those concepts. And therefore we believe to contribute for the future construction of a design system that redefines problem scenarios, rather than providing individual solutions, repositioning architects and clients in the design process.
\end{abstract}

Keywords: Customização em massa; Habitação; Comunicação em rede; Variabilidade; Configurador.

\section{Introdução}

Em uma sociedade fundamentalmente urbanizada, e em crescimento, fenômeno que assume proporções relevantes no atual cenário brasileiro, nos deparamos com a necessidade de produção de habitação em massa. Contudo, com o advento da sociedade pós-industrial ou sociedade de informação, decorrente da revolução das tecnologias digitais de informação e comunicação - TIC, essa produção em massa adquire novos contornos.

Em consequência da revolução das TIC, somos hoje indivíduos com amplo acesso a informação, poder de comunicação e manifestação de individualidade, através da comunicação em rede. Também em consequência dessa revolução, vivemos sob um novo paradigma produtivo. A inserção de tecnologias digitais no processo de produção nos aproxima do conceito de customização em massa, como alternativa ao modelo de bases fordistas da sociedade industrial.

Diante deste quadro de transformações, o presente documento apresenta parcialmente os resultados da pesquisa em curso que busca apontar caminhos para a produção arquitetônica contemporânea num contexto onde coexistem: necessidade de produção de habitação em massa e observância à possibilidade de personalização. Neste contexto, os problemas de projeto tornamse mais numerosos e complexos e o esforço de design redireciona seu foco do simples fornecimento de soluções individuais para uma profunda reformulação dos problemas de projeto.

\section{Comunicação em rede}

Evidenciada com a revolução da TIC, a comunicação em rede se caracteriza por uma estrutura onde os diversos pontos de uma malha têm papéis importantes na emissão e recepção da informação, havendo ativa participação de cada indivíduo no processo comunicativo. Especialmente com o advento da internet e mídias sociais, hoje o indivíduo conectado em qualquer parte do globo, tem em suas mãos poderosa ferramenta de expressão de sua individualidade.

Nesse sentido, Lemos (2004) citado por Requena (2007) afirma que o modelo um-todos das mídias tradicionais opõe-se ao modelo todos-todos das mídias digitais, que privilegia uma forma descentralizada e universal de circulação de informações em tempo real. Esta circulação universal e dinâmica permite a disponibilização de informações sobre necessidades e preferências de determinado mercado de clientes, úteis a um processo produtivo que considera a personalização de seus produtos.

\section{Novo paradigma produtivo}

A customização em massa é um paradigma que prega a produção de bens e serviços que atendam a necessidades especificas do cliente, porém com preços, custos de produção e tempo de entrega, similares aos da produção em massa (PINE, 1994).

Na Era Digital, condições como a inserção de tecnologias digitais no processo produtivo industrial e o papel das redes de informação e comunicação como o meio fundamental onde se 
processam transações econômicas, permitem a maior difusão deste novo paradigma produtivo.

\section{Configuradores de produtos}

Ferramentas para viabilização da implantação do modelo de customização em massa, apoiando-se na comunicação em rede, os configuradores são plataformas computacionais, geralmente operadas na internet, que guiam o consumidor durante a definição de determinado produto.

Segundo Hedin, G.; Ohlsson, L. ; McKenna, J. (1998) "A product configurator is a tool which supports the product configuration process so that all the design and configuration rules which are expressed in a product configuration model are guaranteed to be satisfied."

Estas ferramentas permitem, assim, a definição e o gerenciamento de uma variedade de produtos ou soluções, além de contribuir para a administração do fluxo de informações entre os atores clientes e projetistas - no processo de customização. Por estas razões, ferramentas computacionais nos moldes dos configuradores de produtos tem potencial para a aplicação direta do conceito produtivo da customização em massa em determinados contextos de projeto de arquitetura.

\section{Modularização}

$\mathrm{Na}$ aplicação prática do modelo produtivo da customização em massa, é de fundamental importância a determinação do nível da customização oferecida. Schodeck, (2005) afirma que existem diferenças significativas entre a indústria de produção em geral e a indústria construtiva. Estas diferenças relacionam-se, segundo o mesmo autor, à escala dos produtos oferecidos e ao fato de que um produto de consumo é geralmente pré-fabricado enquanto uma edificação consiste em um mix de produtos pré-fabricados e de produtos fabricados no canteiro de obras. Por isso, a determinação deste nível permitido é crucial, pois pode permitir ou inviabilizar economicamente a adoção do sistema dentro de determinada cadeia produtiva.

Como define Schodeck, (2005) a abordagem de projeto modular é uma estratégia aditiva, que proporciona variabilidade de soluções através da combinação de módulos standard que podem por sua vez, ser produzidos em massa. A produção no nível da modularização tem, portanto, a vantagem de aliar um sistema produtivo de base fordista previamente existente ao alcance de certo nível de variabilidade produtiva. A adoção desta estratégia é vantajosa, pois permite uma inserção mais imediata e menos traumática de princípios da customização em massa em uma cadeia produtiva complexa como a da indústria da construção.

\section{Metodologia}

A metodologia utilizada para o desenvolvimento das especificações da ferramenta fundamentou-se na definição de níveis e etapas de uma plataforma computacional, similar a um configurador, para o auxilia de projeto de unidades habitacionais para classe média no mercado brasileiro. A organização da ferramenta em dois níveis teve como base as relações da ferramenta com os dois grupos principais de usuários da mesma: clientes e designers. Os subsídios para essa definição foram derivados de dados da literatura e de pesquisa no mercado imobiliário em relação às necessidades e preferências recorrentes dos usuários.

Para a pesquisa junto a clientes, potenciais compradores de unidades habitacionais da classe media brasileira, foi realizada a aplicação de um piloto de experimento: aplicação de questionário a um grupo alvo reduzido com o objetivo de fomentar a construção de um método para a inserção de dados, preferências e necessidades do usuário no processo de configuração de seu apartamento.

Por outro lado, um levantamento dos mecanismos projetuais recorrentes do mercado imobiliário, junto a empresas de projeto e construtoras fomentaram as definições preliminares das etapas relacionadas à equipe de projetos nas definições do edifício.

\section{Definições de níveis e etapas do configurador}

O primeiro ponto no desenvolvimento da ferramenta, a partir dos dados coletados do mercado foi a organização dos mesmos num algoritmo, uma sequencia lógica de passos, para o configurador de projetos habitacionais. O configurador foi organizado em dois níveis e seis etapas de projeto para o processo de definição de uma unidade de apartamento.

Para embasar estas etapas foi estabelecida de forma preliminar uma gramática da forma, também subsidiada pela pesquisa junto a potenciais clientes e empresas de projeto. Conforme definição de Mark et at.(2008), a abordagem de projeto auxiliado por computador, denominada Shape grammar ou gramática da forma é na pratica um conjunto de regras de produção e de transformação da forma, através de substituições. As regras de produção da forma aplicadas em diferentes ordens irão gerar diferentes variantes num universo formal. Posteriormente, a gramática preliminar especificada será aprimorada, com o desenvolvimento mais aprofundado de seu vocabulário, listagem das regras de transformação formal, agrupadas segundo os níveis e etapas do configurador.

\section{Correlações entre inputs do configurador e regras da gramática formal}

O segundo ponto no desenvolvimento das especificações do configurador é a correlação entre os inputs geralmente textuais gerados pelos usuários do sistema e a aplicação das regras da gramática formal para a geração de soluções arquitetônicas.

Como os inputs do configurador se traduzem por respostas a perguntas diretas feitas ao usuário, cliente, a tarefa realizada foi a de correlacionar determinada resposta do cliente à regra gramatical correspondente aplicada à forma. 


\section{Resultados}

Os resultados foram aqui apresentados em termos de especificações preliminares do configurador de design para unidades de apartamento de classe média brasileira. Essas especificações são traduzidas por instruções para a construção da interface de comunicação com o cliente, através da determinação de etapas a serem seguidas, futuras telas do configurador. As especificações aparecem aqui exemplificadas na apresentação do design simulado e esquemático de uma unidade do edifício de apartamentos hipotético. Esta unidade considerou a ocupação por um único indivíduo ou um casal, através de um único espaço destinado ao dormitório.

\section{Vocabulário Formal e regras da gramatica}

O vocabulário formal advém de pesquisa bibliográfica e da consulta ao mercado, que revelaram uma tipologia de apartamento brasileira de classe média, na Sociedade de Informação. Segundo Marcelo Tramontano (1997), os arquitetos modernos previram uma habitação prototípica, que correspondia a um homem, a uma cidade, a uma paisagem, igualmente prototípicos, cirando um arquétipo, o da habitação-para-todos. Segundo o mesmo autor, a habitação modernista ainda sofria influências da tripartição burguesa originada no século XIX: a divisão interna da habitação em setores social, íntimo e de serviços.

Contudo, no momento atual da sociedade de Informação, a existência de tipos familiares tão variados e as mudanças no modo como desempenhamos certas atividades domésticas, fazem com que esta compartimentação tripartida se mostre obsoleta. No contexto da pesquisa, julga-se mais apropriada uma organização habitacional por atividades realizadas no âmbito da casa, considerando o modo como se realizam estas atividades sob influência da incorporação das tecnologias digitais nos espaço doméstico.

Dentro da estratégia da modularização previamente apresentada, o vocabulário formal traduziu-se por módulos, compreendendo certas atividades predominantemente desempenhadas em cada um deles, agrupados dentro do espaço de habitação.

Quanto às regras da gramatica formal, foram definidos de forma preliminar algumas regras e parâmetros que regerão as transformações dos módulos e a consequente geração da variabilidade arquitetônica. As regras para as transformações formais aqui apresentadas se limitaram a combinação de espaços dentro de uma mesma unidade habitacional.

\section{Níveis e etapas do configurador}

O processo de configuração dentro da ferramenta computacional foi organizado em dois níveis e seis etapas. O primeiro nível, que se relaciona mais diretamente com os clientes, ou seja, com as definições dentro da unidade habitacional, compreende quatro etapas. Este nível é predominantemente operado pelo cliente, futuro habitante da unidade. Já as duas etapas do segundo nível relacionam-se mais ao trabalho da equipe de projeto, na solução das relações entre unidades habitacionais, agrupando-as em um projeto de edifício completo, e coerente, momento bastante crítico de todo o processo.

\section{Nível 01}

Etapa 01 - Definição do tamanho da unidade habitacional.

A etapa inicial do configurador compreende questões diretas aos usuários, gerando respostas objetivas, visando à definição clara do tamanho da unidade habitacional. Entre as questões, figuram as seguintes:

- Número de moradores da unidade habitacional

- Idade dos moradores da unidade habitacional

- Sexo (s) dos moradores

- Relação de parentesco dos moradores

- Existência de planos para ampliação do número de moradores

A conclusão desta etapa gera de forma objetiva o tamanho da unidade habitacional dentro das opções e modulações previamente determinadas. A figura abaixo exemplifica um esquema de unidades habitacionais baseados na modulação previamente estabelecida, onde as dimensões $\underline{\mathrm{d} 1}$ e $\underline{\mathrm{d} 2} \mathbf{d e p e n d e m}$ de definição estrutural específica de projeto, em consonância com a estratégia da modularização.

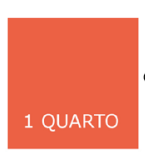

$\mathrm{d} 2$

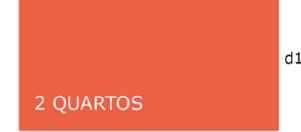

d2 (x2)

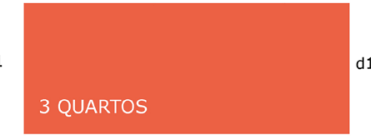

d2 (x2.5)
Figura 1: Esquema modular das unidades de habitação por tamanho. Fonte: (dos autores)

\section{Etapa 02 - Considerações sobre o Estilo de Vida}

A segunda etapa do configurador extrai informações sobre o estilo de vida dos moradores através da atribuição de pesos, valores, a atividades específicas no âmbito doméstico. A atribuição de pesos a atividades busca determinar de forma objetiva o valor da área correspondente a tal atividade. Esta etapa, portanto, define a unidade a partir de atividades desempenhadas e não de cômodos estanques acreditando propiciar esta solução, menor compartimentação da unidade, maior convergência de atividades.

Buscamos também, através dessa definição determinar duas porções dentro da unidade: uma, relativamente estática, que sofre poucas mudanças por ser função direta das necessidades corporais e higiênicas; e outra, maior e mais dinâmica, mutável e re-configurável. 
$\mathrm{Na}$ tentativa de se libertar da compartimentação tripartida tradicional e incorporar à moradia a dinâmica da convergência da sociedade de informação, listamos abaixo cinco possíveis atividades no âmbito do piloto desenvolvido, para a unidade de habitação de um (1) dormitório:

$$
\begin{aligned}
& \text { a - atividade/espaço de cozinhar/comer } \\
& \text { b - atividade/espaço de estudo/trabalho } \\
& \text { c - atividade/espaço de dormir/íntimo } \\
& \text { d - atividade/espaço de receber pessoas } \\
& \text { e - atividade/espaço de higiene íntima/roupas }
\end{aligned}
$$

O resultado desta etapa é semelhante ao ilustrado pelo esquema simplificado abaixo. A atribuição de pesos a cada atividade gera núcleos maiores ou menores, conforme a ilustração. Ao comparamos os exemplos percebemos que a diferença de pesos atribuídos pelo usuário determina diferentes áreas de atividades.

\section{atividades e pesos morador 1}

\section{layout esquematico}

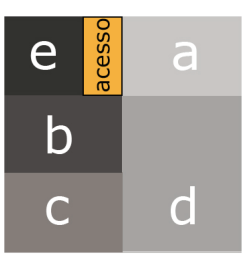

\section{morador 2}

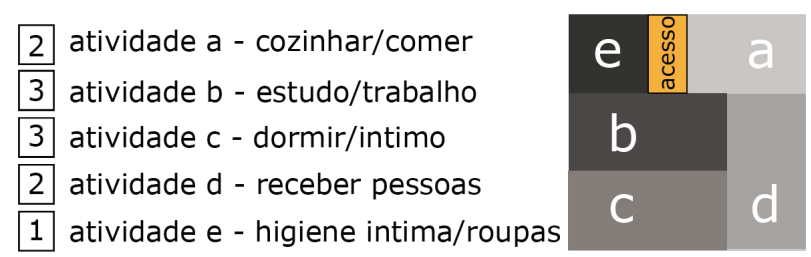

Figura 2: Esquema simplificado da atribuição de pesos a atividades. Fonte: (dos autores)

Etapa 03 - Definição das relações espaciais entre atividades

Esta etapa definirá que atividades podem ocorrer no mesmo espaço, em proximidade, ou de forma isolada. Na prática, o sistema posiciona cada cor de acordo com preferências e aplica regras da gramática de modo a definir a posição relativa das atividades e a existência de fechamentos, separações entre as mesmas. Três são os objetivos desta fase:

1 - posicionar atividades adjacentes segundo preferências.

2 - definir fechamentos entre atividades e características dos mesmos (ex. parede alta, bancada baixa, biombo, etc.)

3 - definir ligações, corredores, portas e conexões entre atividades.
A etapa 03 é definida através de uma sequência de perguntas objetivas. Apresentamos no piloto três destas perguntas

1 - define existência de parede entre a atividade a e a atividade $d$.

2 - define existência de fechamento ou bancada entre a atividade $b$ e a atividade $d$.

3 - define fechamento entre a área a e a atividade c, configurando somente uma área de estudos intima ou um escritório para a recepção de clientes.

Sim $\begin{aligned} & 1 \text { - necessidade de fechamento entre } \\ & \text { a area de dormir (c) e a de receber }\end{aligned}$ pessoas $(d)$ ?

Nao 2 -necessidade de fechamento entre area de estudos (b) e area de dormir (c)?

Sim 3 - atividade cozinhar (a) integrada com atividade receber pessoas (d) ?

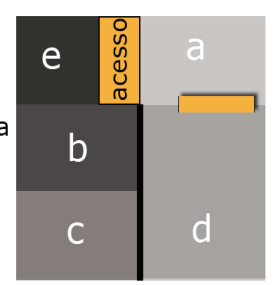

Figura 3: Esquema simplificado da relação entre atividades e tipos de fechamento entre as mesmas. Fonte: (dos autores)

\section{Etapa 04 - Definição de preferências específicas}

Nesta etapa são ofertadas ao cliente escolhas a respeito de materiais, cores, tipos de revestimentos, para personalização mais refinada da unidade habitacional. Este tipo de oferta de customização tem pequeno impacto em termos construtivos, porém a definição da gama de possibilidades ofertadas é de fundamental importância para o gerenciamento logístico e de custos do empreendimento.

A definição destas preferências específicas se relaciona com escolhas do partido arquitetônico, de modo que as opções e combinações de opções são limitadas a condições impostas pelo projetista, de acordo sua intenção projetual.

\section{Nível 02}

Etapa 05 - Definição de um andar - combinação de unidades

Uma das etapas mais críticas no desenho do processo, a combinação de unidades entre si deve buscar a economia de materiais que tem o maior peso no orçamento da construção, bem como a racionalização de circulações e melhor aproveitamento das condições de implantação no terreno. Para isso, abaixo apresentamos preliminarmente, três pontos importantes os quais devem ser resolvidos na combinação de unidades pela ferramenta computacional.

1 - Posicionar núcleos de circulação horizontais e verticais do edifício;

2 - Posicionar núcleos de instalações importantes - água e esgoto em torno dos quais outros sistemas sofrem operações formais de movimentação;

3 - Determinar sistema construtivo e estrutural, com a definição de vãos e posicionamento da malha;

A figura abaixo ilustra esquematicamente uma possibilidade de definição de um pavimento do edifício através do posicionamento 
dos módulos escolhidos por diversos clientes, e da otimização dos núcleos de instalações representados em cor preta, e de circulações, representados em cor laranja:

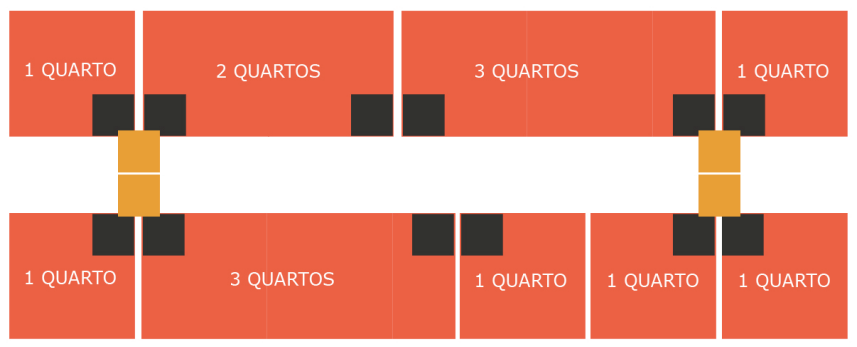

Figura 4: Ilustração do esquema resultado da definição de um andar do edifício com posicionamento de módulos e otimização de núcleos de circulação e instalações. Fonte: (dos autores)

Etapa 06 - Definição de um edifício - combinação de andares

Por último, a combinação de andares em um edifício deve seguir regras estabelecidas pela gramática para otimizar a localização vertical dos núcleos de circulação e instalações, prumadas e etc. Esta última etapa da gramática, visa o objetivo maior: a construção de um edifício com unidade formal e funcional, considerando as implicações volumétricas destas.

Esta definição é de extrema importância, pois guarda muita complexidade e requer a atuação direta do arquiteto. A geração de opções de combinação pela aplicação da gramática possibilitará ao arquiteto a escolha entre as melhores soluções, que mais satisfazem a seus critérios estéticos e de composição.

\section{Conclusão}

Neste artigo, apresentamos os resultados preliminares das especificações de ferramenta computacional para o auxîlio no design de apartamentos para a classe média brasileira que considerem a aplicação do princípio da customizaçao em massa. Acreditamos que a ferramenta concluída poderá ser de grande auxílio no restabelecimento do diálogo proximo entre arquitetos e clientes na Era Digital e que deste dialogo podem emergir soluções mais adequadas às necessidades e preferencias dos indivíduos da Sociedade da Informação.

\section{Referências}

Hedin, G.; Ohlsson, L. ; McKenna, J. (1998): Product Configuration Using Object Oriented Grammars, Heidelberg

Mark, E.; Gross, M.; Goldsmidt, G., (2008). A Perspective on Computer Aided Design after Four Decades, eCAADe 26 Section 04: CAAD Curriculum 1.

Pine II, B. Joseph.(1994). Personalizando Produtos e Serviços: customização maciça. São Paulo: Makron Books do Brasil, 334 p.

Requena, C. A. J.(2007). Habitar Híbrido: Interatividade e Experiência na Era da Cibercultura. Dissertação (Mestrado em Arquitetura e Urbanismo) - Programa de Pós- Graduação - Escola de Engenharia de São Carlos da Universidade de São Paulo, USP, São Carlos, São Paulo.

Schodeck, D., Bechthold, M., Griggs, K., Kao, K.M. \& Steinberg, M.(2005) Digital Design and Manufacturing - CAD/CAM Applications in Architecture and Design, John Willey \& Sons, New Jersey, NJ.

Tramontano, M. (1997). Habitação, hábitos e Habitantes: Tendências contemporâneas metropolitanas. 